\title{
Financial Frictions and Occupational Mobility
}

\author{
William B. Hawkins and José Mustre-del-Río* \\ February 15, 2012 \\ Preliminary and incomplete
}

\begin{abstract}
We study the effects of financial market incompleteness on occupational mobility. Incomplete insurance not only generates an increase in consumption volatility, but also a reduction in occupational mobility and a worsening of occupational matching. The correlation between occupation-level productivity and labor supply is lower than under complete markets. Low-asset workers remain in low-productivity occupations even when the expected value of switching is positive. Negative occupational productivity shocks therefore have larger effects on such workers' future earnings than they would for better insured workers. In a calibrated model, we find that the welfare costs of market incompleteness can be as large as 25 percent of lifetime consumption.
\end{abstract}

JEL: D31, D52, E21, J24

Keywords: occupational mobility, financial frictions, incomplete markets, self-insurance, welfare costs, training subsidies

\section{Introduction}

In the absence of complete markets, the nature of labor income risk is of fundamental importance for understanding the behavior of consumption and wealth in the cross-section and over time. A major source of labor income risk is occupation-level earnings shocks which are large and highly persistent, and therefore difficult for workers to insure against. Worse, market incompleteness potentially magnifies the effects of exogenous income shocks if it affects workers' ability to switch away from occupations hit by negative productivity shocks. In this paper we quantify the importance of financial frictions for occupational mobility and for welfare in a Bewley model. In our benchmark model mobility is 7 percent lower than in a comparable complete markets framework. The welfare costs of market incompleteness are very large: in our benchmark calibration, the average gain from moving to complete markets is 25 percent of lifetime consumption.

\footnotetext{
*Hawkins: University of Rochester, RC Box 270156, Rochester, NY 14627-0156, william.hawkins@rochester.edu. Mustre-del-Río: Economic Research Department, Federal Reserve Bank of Kansas City, jose.mustre-del-rio@kc.frb.org. We would like to thank Mark Bils, Jay Hong, and Ronni Pavan, as well as participants at the Stockman Conference at the University of Rochester for helpful comments. The usual disclaimer applies. The views expressed here are solely those of the authors and do not necessarily represent the views of the Federal Reserve Bank of Kansas City or the Federal Reserve System.
} 
We model occupational choice using an equilibrium search model in the style of Lucas and Prescott (1974), Alvarez and Veracierto (1999), and Kambourov and Manovskii (2009a). The returns to working in an occupation are stochastic, and occupational mobility is costly for three reasons: first, because workers must pay a retraining cost to change occupations, second, because of the opportunity cost of wages forgone while moving, and third, because a worker who starts work in a new occupation loses the occupation-specific human capital she had built up in her former occupation. Unlike the existing literature on occupational mobility, we do not assume that financial markets are complete. Instead, we follow the tradition of Bewley (1986), Huggett (1993), and Aiyagari (1994) and allow agents to self-insure by saving using a risk-free bond. This kind of insurance is only partial, because of the persistence of the shocks and because occupational mobility is undertaken precisely by those workers who have experienced negative shocks to their occupation, and hence, their earnings.

We calibrate the process for occupational-level earnings shocks and the tightness of borrowing constraints to match information on U.S. occupational mobility from the Panel Study of Income Dynamics (PSID). Market incompleteness has substantial effects on occupational mobility. In the benchmark calibration of the incomplete markets model, 15.8 percent of workers move occupations each year, while under complete markets mobility increases to 23.1 percent. Reduced occupational mobility comes at a significant cost in terms of productivity, because more workers work in less productive occupations. Effective labor supply is 8.5 percent higher under complete markets. This is despite the fact that reduced occupational mobility under incomplete markets implies that agents both directly supply more labor and also accumulate more occupation-specific human capital: 84.2 percent of agents are employed and 45.0 percent of agents are experienced in their occupations in this market structure, compared with 76.9 percent and 40.6 percent respectively in the complete markets steady state. The welfare cost of market incompleteness is also very large. As noted already, a randomly-chosen agent drawn from the incomplete markets economy would on average value the opportunity of trading thenceforth in complete insurance markets for her occupational labor productivity risk at 25.0 percent of her lifetime consumption. The welfare costs of incomplete markets mostly arise from greater consumption volatility, as expected in a Bewley model with highly persistent productivity shocks, but are significantly exacerbated by the worsening of occupational match quality just described.

Our paper contributes to several parts of macroeconomics and labor economics. There is a large literature establishing the importance of occupational mobility, in particular for job mobility (Miller, 1984; McCall, 1990) and for wages (Neal, 1995; Parent, 2000; Kambourov and Manovskii, 2009b). Our contribution is to show that incomplete markets are quantitatively relevant for understanding occupational mobility, and therefore also for understanding the cross-sectional distribution of occupational tenure, occupation-specific human capital, and wage dispersion. In our calibrated model, the standard deviation of log wages is 0.667 under incomplete markets, 16 percent greater than the corresponding complete markets value of $0.573 .{ }^{1}$ Market incompleteness thus increases the

\footnotetext{
${ }^{1}$ We abstract for simplicity from other sources of wage dispersion, so that these measures of wage dispersion are
} 
level of cross-sectional wage dispersion implied by occupation-level productivity shocks, implying that these shocks are even more important than suggested by Kambourov and Manovskii (2009a).

Relative to the Bewley class of models, our paper adds a novel feedback mechanism from incomplete markets to the process for future labor income. In the benchmark model, agents' endowment of efficiency units of labor is subject to exogenous shocks, and market incompleteness means that agents' consumption also fluctuates. However, market incompleteness has no effect on the agent's future labor productivity. In our model, on the other hand, because occupational mobility is costly, negative shocks to an agent's labor productivity have different implications for rich and poor agents. Agents far from the lower bound on assets leave an occupation that receives negative shocks when doing so increases their permanent income. Agents near the lower bound, on the other hand, are unable to undertake the costly process of occupational mobility without an unacceptable reduction in their consumption, and so they endogenously end up with lower future labor income. This mechanism by which market incompleteness reduces the ability of some agents to undertake costly investment projects (such as occupational mobility) with positive net present value is closely related to work studying the effect of borrowing constraints on entrepreneurial choice (Evans and Jovanovic, 1989; Quadrini, 2000; Cagetti and De Nardi, 2006; Buera, 2009; Buera and Shin, 2011). ${ }^{2}$

Our paper is more closely related to several papers which allow for workers to respond endogenously to the underlying shocks to their labor productivity. Pijoan-Mas (2006), Marcet, ObiolsHoms, and Weil (2007), and Heathcote, Storesletten, and Violante (2008) allow for workers to make a static labor-leisure choice in response to fluctuations in their labor productivity and asset position. However, in these papers, there is no dynamic component to the labor supply choice made by workers, while in our model the choice to stop supplying labor in a worker's current occupation and undergo a costly reallocation to a new occupation has a dynamic effect on future labor productivity. Technically most closely related to our paper but substantially different in emphasis is the work of Krusell et al. (2008), who study a model which combines an islands model of search along the lines of Lucas and Prescott (1974) with incomplete markets as in the Bewley tradition. However, their focus is on understanding flows between employment and non-employment, and not on heterogeneity across different jobs or occupations. Our work is therefore complementary to theirs.

The structure of the remainder of the paper is as follows. In Section 2, we describe the model, including both our incomplete-markets benchmark and a version with complete markets. We describe our calibration strategy in Section 3. In Section 5, we report results, focusing on the comparison between complete and incomplete markets. Section 7 shows that the effects of market incompleteness can be greater for young agents, something that is particularly important given the higher

smaller than their empirical counterparts. All agents in the model are ex ante identical, so we do not account for wage dispersion associated with education (Katz and Autor, 1999), gender (Goldin, 2006), other types of ex-ante heterogeneity, job search within occupations (Pavan, 2011), or other types of shocks.

${ }^{2}$ In an overlapping-generations setting, this mechanism could also be important for understanding choices made early in the life-cycle, such as educational choice or once-and-for-all occupational choice, as in Banerjee and Newman (1993) and Filmer and Pritchett (1999). 
frequency of occupational switching among the young. Section 8 concludes briefly.

\section{Model}

In this section we describe the economic environments that we consider. To simplify the exposition, we will describe only steady-state versions of our economy. The economy is set in discrete time.

\section{$2.1 \quad$ Preferences}

There is a continuum of workers of fixed measure, normalized to one. Workers are infinitely-lived, and derive utility from consumption $c$. They discount the future with discount factor $\beta \in(0,1)$. The felicity function is denoted $u(c)$, and the expected utility function is given by $\sum_{t=\tau}^{\infty} \beta^{t} u\left(c_{t}\right)$.

\subsection{Occupations}

There is a continuum of islands, which we think of as representing occupations. Islands are indexed by $i \in[0,1]$. Each island $i$ is characterized at any time $t$ by an island-specific labor-augmenting productivity shock $x_{i t}$, which takes values in a finite set $X \equiv\left\{x_{1}, x_{2}, \ldots, x_{M}\right\} . x_{i}$ follows a firstorder Markov process; write $F\left(x, x^{\prime}\right)$ for the probability that $x_{i, t+1} \leq x^{\prime}$ conditional on $x_{i t}=x$. Since we focus only on steady-state equilibria, we assume without loss of generality that the Markov process $F(\cdot)$ has a unique ergodic distribution with full support. Denote the ergodic distribution by $\Psi(\cdot)$.

There is a representative firm on each island $i$. The firm rents capital and labor and produces output; all firms in the economy produce the same final good. A firm on island $i$ that uses $k$ units of capital and $l$ efficiency units of labor in period $t$ when the island-specific productivity shock takes value $x$ produces

$$
Y(k, l) \equiv k^{\alpha} l^{1-\alpha}
$$

units of the final good, where $\alpha \in(0,1)$. The firm is a price-taker in the rental market for capital. Capital is owned by workers, and rented each period to firms; it is not island-specific and can be costlessly reallocated across firms and between islands from period to period. Capital depreciates at rate $\delta \in(0,1)$. Likewise, the firm is a price-taker in the rental market for labor. Labor supply to the firm comes from aggregating the efficiency units of labor supplied by those workers located on island $i$ who do not switch islands in period $t$. Finally, the firm is also a price-taker in the final good market. We normalize the price of the final good to 1.

\subsection{Occupational Mobility}

At the beginning of each period, a nonnegative measure of workers is located on each island. Each period, a worker who remains on the island during the period inelastically supplies $\bar{h}$ units of raw labor. Workers can be either inexperienced or experienced in the occupation that is undertaken 
on island $i$. Workers who are experienced are more productive, so that their labor is $1+\chi>1$ times as productive as the labor of inexperienced workers. ${ }^{3}$ The occupation productivity shock is labor-augmenting, so that on an island with productivity $x$, each inexperienced worker can supply $x \bar{h}$ efficiency units of labor, and each experienced worker $(1+\chi) x \bar{h}$ efficiency units.

A worker who is inexperienced in the occupation associated with island $i$ becomes experienced with probability $q \in(0,1]$ each period that she remains and works on island $i$. The stochastic process of gaining experience conditional on remaining on an island is iid across workers, across islands, and over time. It is convenient to denote a worker's experience by $e$, with $e=1$ if a worker is experienced and $e=0$ otherwise. Define $G\left(e, e^{\prime}\right)$ to be the probability that next period's experience level will be $e^{\prime}$ conditional on today's experience $e$; the discussion above establishes that $G(0,0)=1-q, G(0,1)=q, G(1,0)=0$, and $G(1,1)=1$.

Each period, at the beginning of the period before supplying labor to a firm on this island, with probability $p \in[0,1]$ a worker gets an opportunity to move to another island. ${ }^{4}$ In this case, the worker has the option to move to one specific alternative island $i^{\prime}$. The worker does not have to take up the option, and if she ignores it, she remains on her current island and can supply labor as usual during the current period. Write $\Psi^{m}(\cdot)$ for the cdf of island productivity across the islands the agent might arrive on next period, and $\psi^{m}(\cdot)$ for the corresponding pdf. We assume that at the time of deciding whether or not to accept the mobility opportunity, the worker only knows the distribution $\Psi^{m}(\cdot)$ and not the realization of $x_{i, t+1}$.

If the worker decides to move, she pays a mobility $\operatorname{cost} \kappa$ and does not work during the current period. (The assumption that the agent does not work is intended to model the idea that it might take time for the worker to find a new job in her new occupation, the required time for retraining, and the possibility of lower wages during an 'apprenticeship' period.) At the beginning of the next period, the worker will be located on her new island. Because we assume that human capital is specific to each occupation, she will be inexperienced.

\subsection{Incomplete markets model}

In our benchmark model, we assume that there are incomplete markets, following Huggett (1993) and Aiyagari (1994). There are no state-contingent markets to insure either against the occupation productivity shock or the idiosyncratic experience shock. A worker holds assets $a$, which can never be lower than a lower bound $\underline{a}$, which can either be the natural borrowing limit or a strictly greater exogenous limit.

The state variables for an individual worker in the incomplete markets economy are the productivity of the island on which she is located, $x$, whether or not she is experienced in her island's occupation, $e$, and her assets, $a$. We write $e=0$ for an inexperienced agent and $e=1$ for an experienced agent. The Bellman value $V(x, e, a)$ of a worker who begins a period in state $(x, e, a)$

\footnotetext{
${ }^{3}$ This simple way of modeling the return to occupational tenure follows Kambourov and Manovskii (2009a).

${ }^{4}$ We have in mind that the worker hears about from a personal contact network about the prospects in a particular occupation. We set $p=1$ in our benchmark calibration; allowing for $p<1$ serves to reduce occupational mobility conditional on the volatility of occupational productivity shocks in a straightforward way.
} 
satisfies

$$
V(x, e, a)=p \max \left\{V_{w}(x, e, a), V_{m}(a)\right\}+(1-p) V_{w}(x, e, a)
$$

where $V_{w}(x, e, a)$ is the value of working on the current island, and $V_{m}(a)$ is the value of leaving the current island and moving to a new island, an option that is only available if a mobility opportunity has arrived, which happens with probability $p$. The value of working satisfies

$$
\begin{aligned}
& \qquad V_{w}(x, e, a)=\max _{c, a^{\prime}} u(c)+\beta \sum_{x^{\prime}} \sum_{e^{\prime}} V\left(x^{\prime}, e^{\prime}, a^{\prime}\right) F\left(x, x^{\prime}\right) G\left(e, e^{\prime}\right) \\
& \text { s.t. } \quad c+a^{\prime}=(1+r) a+(1+\chi)^{e} x w \bar{h} \\
& \quad a^{\prime} \geq \underline{a} \quad \text { and } \quad c \geq 0 .
\end{aligned}
$$

The value of moving is

$$
\begin{aligned}
& \qquad V_{m}(a)=\max _{c, a^{\prime}} u(c)+\beta \sum V\left(x^{\prime}, 0, a^{\prime}\right) \psi^{m}\left(x^{\prime}\right) \\
& \text { s.t. } \quad c+a^{\prime}=(1+r) a-\kappa \\
& \quad a^{\prime} \geq \underline{a} \quad \text { and } \quad c \geq 0 .
\end{aligned}
$$

The worker takes as given the interest rate on assets $r$ and the wage per efficiency unit of labor $w$. We write $g^{a}(x, e, a)=a^{\prime}(x, e, a)$ for the savings policy of an agent in state $(x, e, a), g^{c}(x, e, a)$ for the consumption policy, and $m(x, e, a)$ for her mobility decision (setting $m(x, e, a)=1$ if and only if the agent moves when she receives a mobility opportunity).

Because of the non-convexity introduced by the option to move islands, characterizing the solution to this problem analytically is not entirely straightforward. ${ }^{5}$ We therefore use a numerical approach to understanding the model. In our simulations, when $\beta(1+r)<1$ and $u(\cdot)$ has constant coefficient of relative risk aversion no less than 1 , there is a unique solution for the value functions $V(\cdot), V^{w}(\cdot)$, and $V^{m}(\cdot)$, as well as for the mobility policy $m(x, e, a)$ and the savings policy $g^{a}(\cdot)$. Moreover, there is $\bar{a}>\underline{a}$ such that for all $(x, e, a)$ with $a \in[\underline{a}, \bar{a}], g^{a}(x, e, a) \in[\underline{a}, \bar{a}]$.

Given the mobility and savings policies of agents, the process for individual state variables is Markov. If $S$ is a Borel ${ }^{6}$ subset of $Y=X \times\{0,1\} \times[\underline{a}, \bar{a}]$, write $P(x, e, a, S)$ for the probability

\footnotetext{
${ }^{5}$ If mobility were exogenous, the problem reduces to a standard income fluctuations problem as in Huggett (1993) and Aiyagari (1994). It can then be shown as in Proposition 4 of Aiyagari (1993) that if $\beta(1+r)<1$ and the coefficient of relative risk aversion is bounded above as $c \rightarrow \infty$, then there is a unique solution for the value functions $V(\cdot), V^{w}(\cdot)$, and $V^{m}(\cdot)$ and for the savings policy $g^{a}(\cdot)$, and that there is an upper bound on assets. However, the introduction of endogenous mobility introduces a nonconvexity, which makes standard tools of dynamic programming inapplicable, and in particular, it is no longer true, for example, that $g^{a}(x, e, a)$ need be monotone in $a$. The issue is not that mobility is not chosen from a convex set - that could be handled in the usual way by allowing for lotteries over mobility - but that as in Buera (2007) and Vereshchagina and Hopenhayn (2009), the agent's value of assets depends on whether she moves occupation or not. This gives rise to a nonmonotonic savings policy as a function of current assets, and would also lead to a demand for lotteries over wealth. Given the quantitative goal of our paper, we do not allow for lotteries and we do not formally establish conditions under which the properties of the value and policy functions described in the main text hold.

${ }^{6}$ The topology on $Y$ is the product of the discrete topologies on the two finite sets $X$ and $\{0,1\}$ and the standard Euclidean topology on $[\underline{a}, \bar{a}]$.
} 
that $\left(x^{\prime}, e^{\prime}, a^{\prime}\right)$ lies in $S$, that is,

$$
P(x, e, a, S)=\sum_{\left(x^{\prime}, e^{\prime}\right) \mid\left(x^{\prime}, e^{\prime}, g^{a}(x, e, a)\right) \in S} F\left(x, x^{\prime}\right)
$$

Then given the probability measure $\mu$ for today's states $(x, e, a)$, the probability measure for next period's states, $\mu^{\prime}$, satisfies

$$
\mu^{\prime}(S)=\int_{X \times\{0,1\} \times[\underline{a}, \bar{a}]} P(x, e, a, S) d \mu(x, e, a) .
$$

A steady-state equilibrium under incomplete markets is a set of functions $\left\{V(\cdot), V_{w}(\cdot), V_{m}(\cdot), g^{a}(\cdot), g^{c}(\cdot), m(\cdot)\right\}$, a measure $\mu$, aggregate capital and labor $K$ and $L$, and prices $w$ and $r$ such that

1. given the prices $w$ and $r$, the functions $\left\{V(\cdot), V_{w}(\cdot), V_{m}(\cdot), g^{a}(\cdot), g^{c}(\cdot), m(\cdot)\right\}$ solve the household's decision problem;

2. prices equal marginal productivities, $w=Y_{L}(K, L)$ and $r=Y_{K}(K, L)-\delta$;

3. factor markets clear, $L=\int(1-m(x, e, a))(1+\chi)^{e} x d \mu(x, e, a)$ and $K=\int g^{a}(x, e, a) d \mu(x, e, a)$; and

4. the measure $\mu$ is invariant, $\mu(S)=\int_{X \times\{0,1\} \times[\underline{a}, \bar{a}]} P(x, e, a, S) d \mu(x, e, a)$.

Market clearing in the market for the produced good follows from Walras' law. ${ }^{7}$

\subsection{Complete markets model}

Under complete markets, the economic environment is unchanged from that described above, with the exception that we now allow for complete markets for both occupational productivity shocks and idiosyncratic shocks.

We implement complete markets using trade in Arrow securities. We assume that agents invest in Arrow securities which pay off in the following period conditional on the occupational productivity shock $x^{\prime}$ and experience level $e^{\prime}$ which will apply to the agent in that period. Denote by $b^{\prime}\left(x^{\prime}, e^{\prime}\right)$ the number of units of the Arrow security corresponding to state $\left(x^{\prime}, e^{\prime}\right)$ purchased by the agent in the current period; there is an Arrow security for each possible (joint) realization of $\left(x^{\prime}, e^{\prime}\right)$. Because the probability of state $\left(x^{\prime}, e^{\prime}\right)$ depends on whether the agent works or moves during the current period, we assume that the markets for trading these Arrow securities $\left\{b^{\prime}\left(x^{\prime}, e^{\prime}\right)\right\}$ open only after the agent has committed to her decision of whether or not to move occupations. This implies that the prices of the Arrow securities will depend on the agent's mobility choice. Denote by $q^{w}\left(x, e, x^{\prime}, e^{\prime}\right)$ the price of a security paying off in state $\left(x^{\prime}, e^{\prime}\right)$ given that the agent's current state is $(x, e)$ and that she works on her current island, and by $q^{m}\left(x^{\prime}\right)$ the price of a security paying off in state $\left(x^{\prime}, 0\right)$ when the agent moves.

\footnotetext{
${ }^{7}$ To aid comparison, the form of the equilibrium definition is very similar to that in Pijoan-Mas (2006).
} 
The agent enters the current period with a payment $b(x, e)$ from the Arrow security she invested in for the realized state $(x, e)$ in the previous period. The agent's problem can be written

$$
\tilde{V}(x, e, b)=p \max \left\{\tilde{V}_{w}(x, e, b), V_{m}(b)\right\}+(1-p) \tilde{V}_{w}(x, e, b)
$$

where $\tilde{V}_{w}(x, e, a)$ is the value of working and $\tilde{V}_{m}(b)$ is the value of leaving. These values in turn satisfy

$$
\begin{aligned}
& \tilde{V}_{w}(x, e, b)=\max _{c \geq 0, b^{\prime}(\cdot)} u(c)+\beta \sum_{x^{\prime}} \sum_{e^{\prime}} \tilde{V}\left(x^{\prime}, e^{\prime}, b^{\prime}\left(x^{\prime}, e^{\prime}\right)\right) F\left(x, x^{\prime}\right) G\left(e, e^{\prime}\right) \\
& \text { s.t. } \quad c+\sum_{x^{\prime}, e^{\prime}} q^{w}\left(x, e, x^{\prime}, e^{\prime}\right) b\left(x^{\prime}, e^{\prime}\right)=(1+\chi) x w \bar{h}+b
\end{aligned}
$$

and

$$
\begin{aligned}
\tilde{V}_{m}(a) & =\max _{c \geq 0, b^{\prime}(\cdot)} u(c)+\beta \sum \tilde{V}\left(x^{\prime}, 0, a^{\prime}\right) \psi^{m}\left(x^{\prime}\right) \\
\text { s.t. } \quad c & =(1+r) a-a^{\prime}-\kappa
\end{aligned}
$$

where in each case we also impose the natural debt limit to prevent Ponzi schemes. Write the policy functions for the agent as $\tilde{m}(x, e), c=\tilde{g}^{c}(x, e)$, and $b^{\prime}\left(x^{\prime}, e^{\prime}\right)=\tilde{g}^{b}\left(x, e, b, x^{\prime}, e^{\prime}\right)$. Write $\Gamma\left(x, e, x^{\prime}, e^{\prime}\right)$ for the probability of state $\left(x^{\prime}, e^{\prime}\right)$ next period conditional on the current state $(x, e)$ and the mobility policy $\tilde{m}(\cdot)$; then

$$
\Gamma\left(x, e, x^{\prime}, e^{\prime}\right)=\left\{\begin{array}{ll}
F\left(x, x^{\prime}\right) G\left(e, e^{\prime}\right) & \tilde{m}(x, e)=0 \\
\psi^{m}(x) \mathbf{1}\left(e^{\prime}=0\right) & \tilde{m}(x, e)=1
\end{array} .\right.
$$

Also write

$$
q\left(x, e, x^{\prime}, e^{\prime}\right)= \begin{cases}q^{w}\left(x^{\prime}, e^{\prime}\right) & \tilde{m}(x, e)=0 \\ q^{m}\left(x^{\prime}\right) & \tilde{m}(x, e)=1 \quad \text { and } \quad e^{\prime}=0\end{cases}
$$

The Euler equation for an agent in state $(x, e, b)$ is

$$
u_{c}(c)=\beta \frac{\Gamma\left(x, e, x^{\prime}, e^{\prime}\right)}{q\left(x, e, x^{\prime}, e^{\prime}\right)} u_{c}\left(c^{\prime}\right)
$$

When insurance markets are competitive, the no-arbitrage condition implies that

$$
q^{w}\left(x, e, x^{\prime}, e^{\prime}\right)=\frac{1}{1+r} F\left(x, x^{\prime}\right) G\left(e, e^{\prime}\right)
$$

and

$$
q^{m}\left(x^{\prime}\right)=\frac{1}{1+r} \psi^{m}\left(x^{\prime}\right)
$$

Substituting into the agent's Euler equation gives that, as is standard under complete markets, 
independently of the realization of $\left(x^{\prime}, e^{\prime}\right)$,

$$
u_{c}(c)=\beta(1+r) u_{c}\left(c^{\prime}\right)
$$

This implies that $\beta(1+r)=1$ is a necessary condition for a steady-state equilibrium (although we can consider the problem of an individual agent more generally; this will be useful in understanding the welfare gains associated with completing markets).

Finally, as under incomplete markets, we can define a law of motion $\tilde{P}(\cdot)$ so that for any $x \in X$, $e \in\{0,1\}, b \in \mathbf{R}$ and any Borel subset $S$ of $X \times\{0,1\} \times \mathbf{R}, \tilde{P}(x, e, b, S)$ is the probability $\left(x^{\prime}, e^{\prime}, b^{\prime}\right)$ lies in $S$. We also have an associated law of motion for the measure of agents over $X \times\{0,1\} \times \mathbf{R}$, defined analogously to (2) above.

A steady state equilibrium under complete markets is a set of functions $\left\{\tilde{V}(\cdot), \tilde{V}_{w}(\cdot), \tilde{V}_{m}(\cdot), \tilde{g}^{b}(\cdot), \tilde{g}^{c}(\cdot), \tilde{m}(\cdot)\right\}$, a measure $\tilde{\mu}$, aggregate capital and labor $K$ and $L$, and prices $w, r, q^{w}(\cdot)$, and $q^{m}(\cdot)$ such that

1. given the prices $w, r, q^{w}(\cdot)$, and $q^{m}(\cdot)$, the functions $\left\{\tilde{V}(\cdot), \tilde{V}_{w}(\cdot), \tilde{V}_{m}(\cdot), \tilde{g}^{b}(\cdot), \tilde{g}^{c}(\cdot), \tilde{m}(\cdot)\right\}$ solve the household's decision problem;

2. prices equal marginal productivities, $w=Y_{L}(K, L)$ and $r=Y_{K}(K, L)-\delta$;

3. factor markets clear, $L=\int(1-\tilde{m}(x, e, b))(1+\chi)^{e} x d \tilde{\mu}(x, e, b)$ and $K=\int\left[\sum_{x^{\prime}, e^{\prime}} q\left(x, e, x^{\prime}, e^{\prime}\right) g^{b}(x, e, b)\right] d \tilde{\mu}(x, e, a)$

4. insurance is competitively priced, $q^{w}\left(x, e, x^{\prime}, e^{\prime}\right)=\frac{1}{1+r} F\left(x, x^{\prime}\right) G\left(e, e^{\prime}\right)$ and $q^{m}\left(x^{\prime}\right)=\frac{1}{1+r} \psi^{m}\left(x^{\prime}\right)$;

5. $\beta(1+r)=1$; and

6. the measure $\mu$ is invariant, $\mu(S)=\int_{X \times\{0,1\} \times \mathbf{R}} \tilde{P}(x, e, b, S) d \mu(x, e, b)$.

Market clearing in the market for the produced good again follows from Walras' law.

\section{Calibration}

\section{Model Parametrization and Calibration}

In this section we describe the model parametrization and calibration procedure.

\subsection{Parametrization}

We assume that the model period is one year in order to minimize computational time, given the complicated nature of our model. In future work, we plan to recast the model at a quarterly frequency. Utility is logarithmic, $u(c)=\log (c)$, to allow for a balanced growth path. In addition, no borrowing is not allowed, $\underline{a}=0 .{ }^{8}$ Search is partially directed, so that the next-period productivity

\footnotetext{
${ }^{8}$ We will investigate the robustness of the results to this assumption in a future version of this paper.
} 
$x_{i^{\prime}, t+1}$ of the destination island $i^{\prime}$ is drawn from the top $d$ quantiles of the ergodic distribution of island productivity shocks. That is, we set the distribution of destination islands for agents who move to be:

$$
\Psi^{m}(\xi)= \begin{cases}\frac{\Psi(\xi)-d}{1-d} & \Psi(\xi) \geq d \\ 0 & \text { otherwise }\end{cases}
$$

Note that this formulation nests two extreme cases. If $d=0$, then occupational mobility is fully random, as in Alvarez and Veracierto (1999). If $d=1$ then occupational mobility is fully directed, as in Lucas and Prescott (1974).

Finally, we assume that the first order Markov process for $x$ approximates an AR(1) process of $\log (x)$ :

$$
\log \left(x^{\prime}\right)=\rho_{x} \log (x)+\epsilon_{x} \quad \text { s.t. } \epsilon_{x} \sim N\left(0, \sigma_{x}\right)
$$

\subsection{Calibration}

The main structural parameters of our model are those governing the island productivity shock process $\rho_{x}, \sigma_{x}$; the returns to occupational experience $\chi, q$; the financial cost of moving $\kappa$; and the frequency and directedness of mobility $p, d$. Following Kambourov and Manovskii (2009a) we calibrate $\rho_{x}$ and $\sigma_{x}$ so that the model can replicate the frequency and persistence of occupational mobility observed in the PSID for the 1970-73 period. Specifically, the model reproduces two targets: (1) an average annual rate of occupational mobility at the three-digit level of 15.9 percent; and (2) the average number of switches for those who switched occupations at least once over the period, which is $1.59 .{ }^{9}$ Also, similar to Kambourov and Manovskii (2009a) we calibrate $\chi$ and $q$ so that in the model it takes 10 years of occupational tenure to become experienced and earn a permanent wage increase of 20 percent, relative to inexperienced individuals.

To calibrate the financial cost of moving $\kappa$ we follow evidence from Heckman, Lalonde, and Smith (1999). They report that the average vocational training program in the US takes about three months of study and has a direct cost of $\$ 2,000$ to $\$ 3,000$ in 1997 U.S. dollars. Kambourov and Manovskii (2009a) argue that this monetary cost is close to two months of wages for the median worker in 1997. We take a slightly different approach and set the mobility cost to two months of wages for the mean worker in our model. Unreported robustness exercises show that our main results are robust to modest changes in the mobility cost. Note, however, that casting the model at an annual frequency exaggerates the indirect (time away from work) cost of moving.

A key parameter of the model is $d$, which governs the directedness of search. As previously mentioned, if $d=0$ then search is fully directed, as in Lucas and Prescott (1974), while if $d=1$ then search is fully random, as in Alvarez and Veracierto (1999). Neither extreme assumption seems empirically reasonable. Given our production structure, fully directed search would mean

\footnotetext{
${ }^{9}$ Because both $\rho_{x}$ and $\sigma_{x}$ affect these targets, we use a Simulated Method of Moments (SMM) approach whereby the sum of squared deviations between model-simulated and data moments is minimized.
} 
that there is no wage dispersion among workers conditional on switching occupations. Moreover, the OLS return to occupational tenure would be substantially more negative than the true return to tenure. This is because workers would move only to occupations with maximal productivity, which would then revert to the mean. Alternatively, fully random search means that we would see many workers experience substantial wage cuts upon switching occupations. Mobility into declining occupations would be equally likely as mobility into growing occupations, which is contrary to Şahin et al. (2011). Finally, repeated occupational switches would be common, which is at odds with observations on repeat mobility in the PSID. In future work, we plan to calibrate the parameter $d$ by using the joint distribution of these variables. In the current version of the paper we simply set $d$ at an intermediate value of 0.5 to allow for partially-directed search.

We set the parameter $p$, which governs the frequency with which workers receive mobility opportunities, to 1 . Because we calibrate the model at an annual frequency, reducing $p$ much below 1 would exogenously make mobility too rare.

Last, we set $\alpha, \beta$, and $\delta$ following standard practices in the literature. We calibrate the capital income share $\alpha$ to 0.36 and the annual depreciation rate $\delta$ to 8 percent. Following Chang and Kim (2006), we calibrate $\beta$ so that in equilibrium the annual real interest rate is 4 percent. Table 1 summarizes the calibration targets and parameter values.

\begin{tabular}{|c|c|c|}
\hline Parameter & Target & Value \\
\hline$\alpha$ & Capital income share & 0.36 \\
\hline$\delta$ & Annual depreciation rate & 0.08 \\
\hline$\beta$ & $\begin{array}{l}\text { Annual real } \\
\text { interest rate } r=0.04\end{array}$ & 0.934 \\
\hline$\rho_{x}, \sigma_{x}$ & $\begin{array}{l}\text { 3-digit annual } \\
\text { occupational mobility and } \\
\text { average number of switches for those } \\
\text { who switched occupations at least } \\
\text { once in a 4-year period }\end{array}$ & $0.947, \quad 0.353$ \\
\hline$\kappa$ & $\begin{array}{l}\text { Two months of forgone wages } \\
\text { for mean worker }\end{array}$ & 0.472 \\
\hline$\chi, q$ & $\begin{array}{c}\text { Return to } 10 \text { years of } \\
\text { of occupational experience }\end{array}$ & $0.2, \quad 0.1$ \\
\hline
\end{tabular}

Table 1. Calibration targets and parameter values 

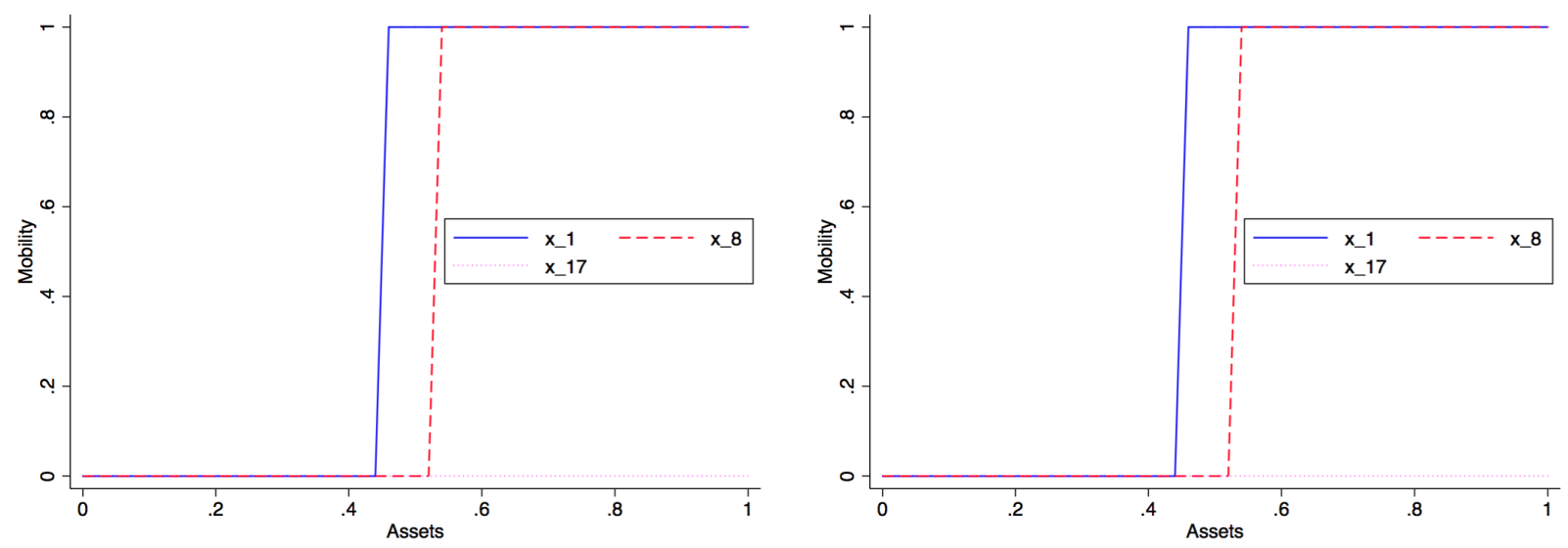

Figure 1. Mobility policies for inexperienced (left) and experienced individuals (right), incomplete markets.

\section{Results}

In this section we present our results on the effects of market incompleteness on occupational mobility, occupational tenure, and welfare. We do this by presenting comparisons between complete and incomplete markets economies.

\subsection{Occupational Mobility Policies}

We begin by describing the policy functions for occupational mobility under the two market environments. Figure 1 depicts the mobility policies in the incomplete markets model graphically. The left panel of the figure shows the mobility policy $m(x, 0, a)$ for inexperienced agents; the right panel shows the corresponding policy $m(x, 1, a)$ for experienced agents. On the horizontal axis of each graph are assets $a$ (in absolute units); the mobility policies for different $x$ values are shown using different line styles. Recall that $m(x, e, a)$ takes values of either zero or one. The graphs show that mobility is increasing in assets. For the lowest island productivity $x_{1}$, agents with the ability to pay the mobility cost (that is, with $a>\kappa$ ) almost all choose to move. For a higher island productivity $x_{8}$, the asset threshold at which agents switch occupations increases. Agents with more assets are more willing to wait and see whether the island productivity improves, rather than pay the mobility cost $\kappa$. Finally, agents on an island with very high productivity $x_{17}$ do not move.

Under complete markets, mobility is independent of assets and agents act to maximize the present discounted value of income. This requires that all agents move away from all islands with productivity less than a threshold value.

\section{$5.2 \quad$ Economic aggregates}

Table 2 reports results for the basic economic aggregates. The capital stock is higher in steady state in the benchmark than under complete markets; this is a standard result in Bewley models, 


\begin{tabular}{cccccccc}
\hline Variable & $K$ & $Y$ & $C$ & Mob. rate & Frac. exper. & $L$ (Raw) & $L$ (Eff. units) \\
\hline Benchmark & 11.2 & 3.73 & 2.76 & 0.157 & 0.450 & 0.843 & 2.01 \\
Complete markets & 8.55 & 3.56 & 2.78 & 0.231 & 0.406 & 0.769 & 2.18 \\
(CM/IM)-1 & -0.24 & -0.04 & 0.01 & 0.47 & -0.10 & -0.09 & 0.08 \\
\hline
\end{tabular}

Table 2. Economic Aggregates

\begin{tabular}{ccc}
\hline Variable & $w$ & $r$ \\
\hline Benchmark & 1.19 & 0.0400 \\
Complete markets & 1.05 & 0.0703 \\
(CM/IM)-1 & -0.12 & 0.76 \\
\hline
\end{tabular}

Table 3. Prices

although given that effective labor supply is endogenous to the mobility decisions of agents, it was not guaranteed here (Marcet, Obiols-Homs, and Weil, 2007). The lower capital stock leads to slightly lower aggregate output, despite the slightly higher effective labor supply that arises from greater occupational mobility under complete markets. Consumption is slightly higher under complete markets despite the lower aggregate output, consistent with lower depreciation as a result of the lower capital stock.

Much more striking are the differences in mobility rates across the two market environments. Mobility is 47 percent higher in the complete markets steady state, as agents move whenever it increases the present discounted value of labor income. Under incomplete markets, the need to smooth consumption by conserving assets and not paying the mobility cost and forgoing earnings looms larger. The flip side of higher mobility is lower raw labor supply (these variables sum to unity by construction). It also ensures that agents are less likely to have become experienced in their occupation under complete markets. Despite these two offsetting forces, the distribution of agents across island productivities is much improved under complete markets, leading to an effective labor supply 8 percent higher under complete markets.

Table 3 reports the corresponding results for prices. The lower aggregate capital stock and higher effective labor supply under incomplete markets lead to a sharp increase in the marginal product of capital, and hence in the interest rate. There is a corresponding reduction in the marginal product of labor and the wage.

\subsection{Cross-sectional features}

The most striking effect of the market environment is that under complete markets, agents are much more concentrated on productive islands. The left panel of Figure 2 shows this graphically. It is immediately apparent that the distribution of agents across islands under complete markets dominates that in the benchmark, in the sense of first-order stochastic dominance.

The reason for the improvement in the distribution of workers over island productivity under 

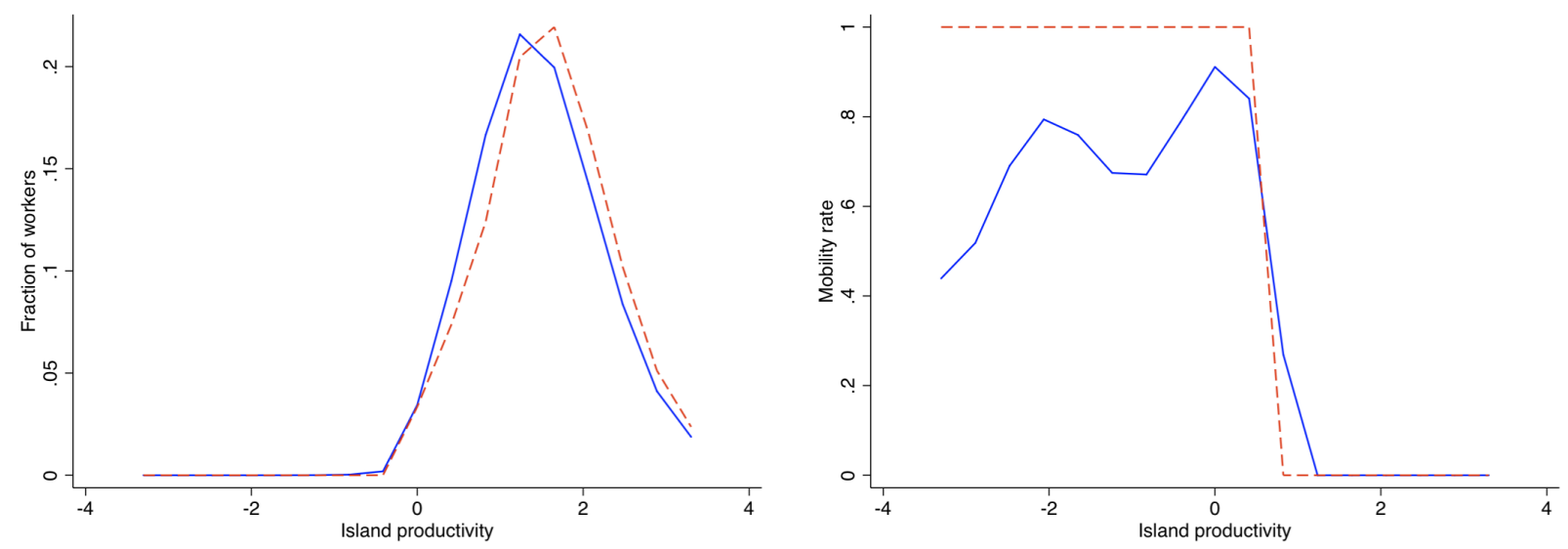

Figure 2. Left panel: Distribution of workers by island productivity. Right panel: Mobility rate by island productivity.

(Blue solid line: benchmark; red dashed line: complete markets.)

complete markets must arise from a difference in the probability of occupational switching conditional on island productivity in that environment. This can be seen directly in the right panel of Figure 2. Under complete markets, agents leave an occupation if and only if its productivity falls below the threshold at which the expected present discounted value of future labor income, net of mobility costs, is increased by moving. When markets are incomplete, however, agents do not move as frequently. Agents on low-productivity islands likely have low assets, due to a history of negative productivity shocks leading to repeated costly mobility.

Under incomplete markets, uninsurable labor income risk implies that consumption varies both in the cross-section and over time for each individual agent. Table 4 reports key statistics on consumption, and Figure 3 shows histograms of consumption and consumption growth in the crosssection. As can be seen, the cross-sectional variance of consumption is very high, and consumption is volatile and highly correlated with current income, assets, and island productivity, all of which indicate that markets are substantially incomplete.

By contrast, in the steady state under complete markets, consumption is constant for each individual agent, but the cross-sectional variance of consumption is not uniquely determined. Throughout the paper, we report consumption statistics for the complete markets model that arises after the completion of a transition process of an economy which begins in the steady state of our benchmark incomplete markets model, in which at time 0 complete markets for future idiosyncratic and occupational risk are opened. The wealth of an agent in this model is given by the expected present discounted value of her future labor income net of mobility costs, plus her assets inherited from the incomplete markets environment. She chooses future mobility to maximize the present value of her income, then chooses consumption according to her lifetime budget constraint. This generates a cross-sectional dispersion in consumption of 0.35 . Because mobility is independent of wealth, consumption in the complete markets steady state is therefore uncorrelated with labor income, earnings, assets, or island productivity, and is perfectly autocorrelated. 


\begin{tabular}{ccc}
\hline Statistic & $\begin{array}{c}\text { Incomplete } \\
\text { Markets }\end{array}$ & $\begin{array}{c}\text { Complete } \\
\text { Markets }\end{array}$ \\
\hline Variance of log consumption & 0.72 & 0.05 \\
Variance of consumption growth & 0.07 & 0.00 \\
Autocorrelation of log consumption & 0.93 & 1.00 \\
Correlation of log consumption with labor income & 0.86 & 0.00 \\
Correlation with earnings & 0.83 & 0.00 \\
Correlation with assets & 0.94 & 0.00 \\
Correlation with island productivity & 0.63 & 0.00 \\
\hline
\end{tabular}

Notes: Statistics derived from a simulated panel of 50,000 individuals. Island productivity in levels.

Table 4. Cross-sectional consumption statistics
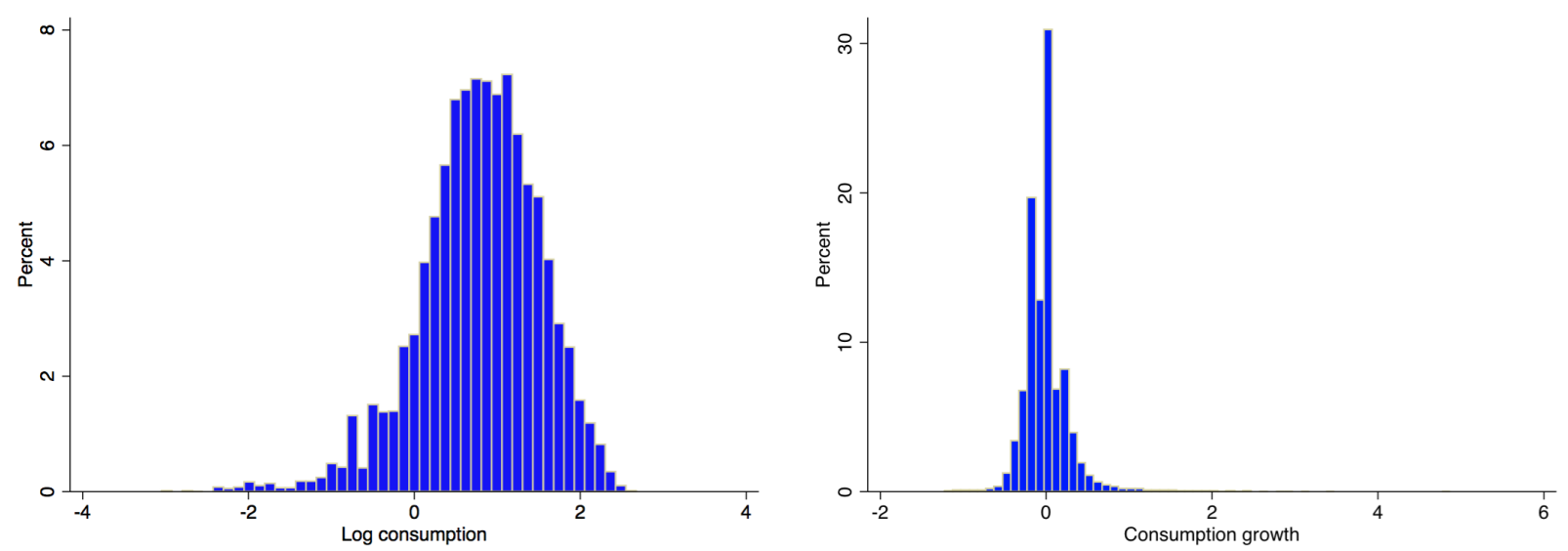

Figure 3. Left panel: Simulated consumption histogram, incomplete markets.

Right panel: Simulated consumption growth histogram, incomplete markets. 


\subsection{Welfare cost of incomplete markets}

\subsubsection{Comparison of steady states}

Our main results concern the welfare gains of complete markets in the model of occupational mobility that we study. We measure welfare gains as equivalent variation: what fraction would we need to increase an agent's consumption in every period under incomplete markets so as to make her indifferent to suddenly being transferred, with her current island productivity and assets, into the steady state of the complete markets economy? Table 5 reports the basic result that the average welfare gains are very large, and average 25 percent of consumption.

There is some variation across agents in the gains from introducing complete markets, which arises from the heterogeneity in current island productivity, experience, and assets at the time of the introduction. This variation can be seen in Figure 4, which reports the average welfare gains conditional on assets, and Figure 5, which reports the average welfare gains conditional on island productivity and experience. In Figure 4, we show the gains for agents with three different island productivity levels $x_{10}<x_{13}<x_{17}$, respectively the tenth percentile, the median, and the maximum of the ergodic distribution of agents across island productivities.

The benefits of complete markets are most pronounced for those with low assets and those located on unproductive islands, who gain from two sources: they can immediately make occupational switches to more productive islands which increase the present value of their labor income (net of mobility costs), and they can increase their consumption by borrowing against their future labor income. It is noticeable also that agents with high assets gain substantially from the transition to complete markets. This is a general equilibrium effect: because the capital stock is substantially lower under complete markets, the interest rate rises, benefiting agents who hold substantial assets when complete markets are introduced.

To make these intuitions more precise, we also report welfare effects from two experiments that aim to distinguish the pure partial equilibrium effect of completing markets from the pure general equilibrium effect of price changes. We define the price-constant, partial equilibrium welfare gain as the equivalent variation associated with providing the agent with complete markets against idiosyncratic and occupational risk, but holding factor prices $w$ and $r$ constant at the levels associated with the benchmark incomplete-markets steady state. We define the general equilibrium welfare gain as the equivalent variation associated with preserving the incomplete market structure of the benchmark model, but exogenously altering prices to the values they take under the complete markets steady state. (Of course, neither experiment is consistent with steady-state equilibrium, since prices are endogenous in this model, but we can still calculate welfare gains for agents exogenously subject to such prices and market structures.)

The price-constant gains exceed the full welfare gains: they are as high as 42 percent. Again there is substantial variation in the distribution of these gains across agents. Rich agents no longer benefit from a high interest rate, but the gains for poor agents are enhanced (because the wage per efficiency unit of labor is higher under incomplete markets, due to the higher capital stock). 


\begin{tabular}{lccc}
\hline & Overall & PE component & GE component \\
\hline Average equivalent consumption variation & 0.25 & 0.42 & 0.04 \\
Standard deviation of consumption variation & 0.08 & 0.18 & 0.06 \\
\hline
\end{tabular}

Table 5. Average Welfare Gains
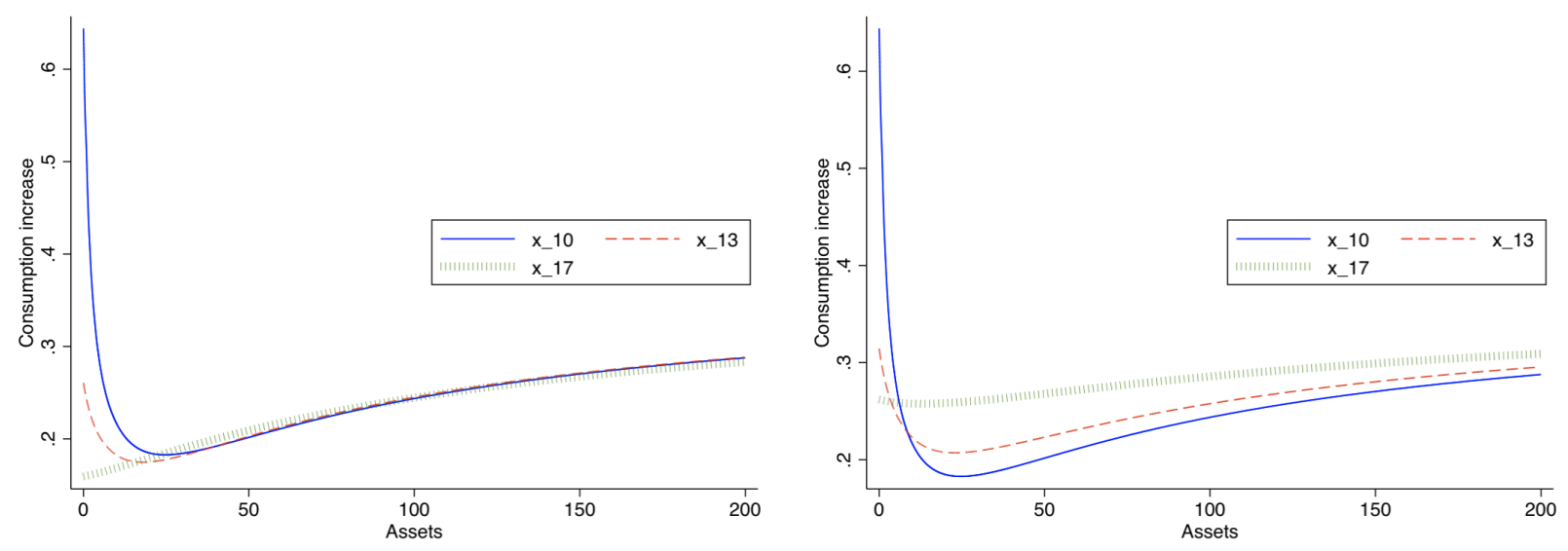

Figure 4. Overall welfare gains for inexperienced (left) and experienced (right) individuals.

The distribution of price-constant welfare gains by assets is shown in Figure 6, and that by island productivity and experience as the uppermost curve in Figure 8. The general equilibrium effects are relatively small, 4 percent on average, and mostly arise from the large change in the interest rate, which particularly benefits rich agents. This can be seen in Figure 7 and the lowest curve in Figure 8.

\subsubsection{Allowing for the transition}

Welfare gains are slightly higher if we allow for the transition to the steady state after the introduction of complete markets for idiosyncratic and occupational risk into the incomplete markets steady state. The reason for this is the same as in Pijoan-Mas (2006): the capital stock is higher in the steady state of the benchmark incomplete markets economy, and during the transition, agents consume this capital stock. In addition, there is a period while capital remains higher than in the steady state, which increases wages and reduces the interest rate. This benefits especially those agents who are located on productive islands when the transition begins.

We do not report numerical values for the additional welfare gain associated with the transition in the current version of the paper; these will be added in the next version. The time path for the transition of the key aggregate variables, $K$ and $L$, as well as the key prices $r$ and $w$, can be seen in Figure 9. Variables are shown as log deviations from their complete-markets steady state values. Notice that labor rises during the transition, as agents choose mobility policies that are not constrained by their asset position. 


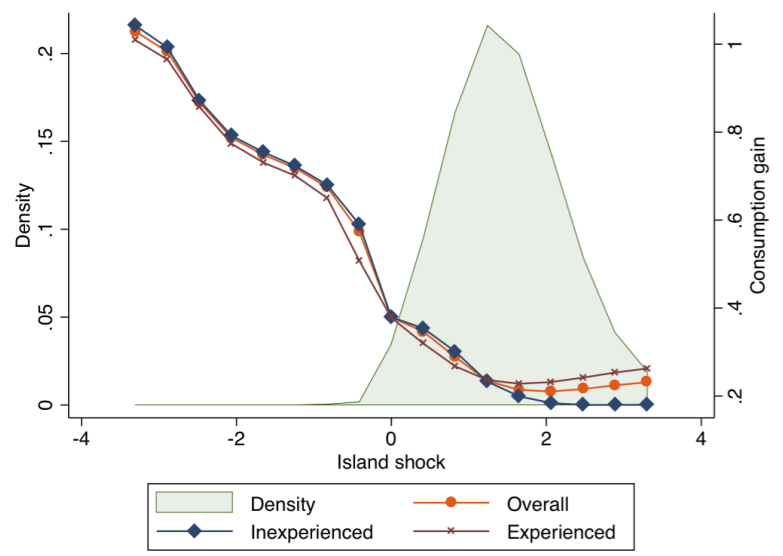

Figure 5. Distribution of welfare gains by island and experience (right scale).

Shaded: distribution of individuals across islands (left scale).
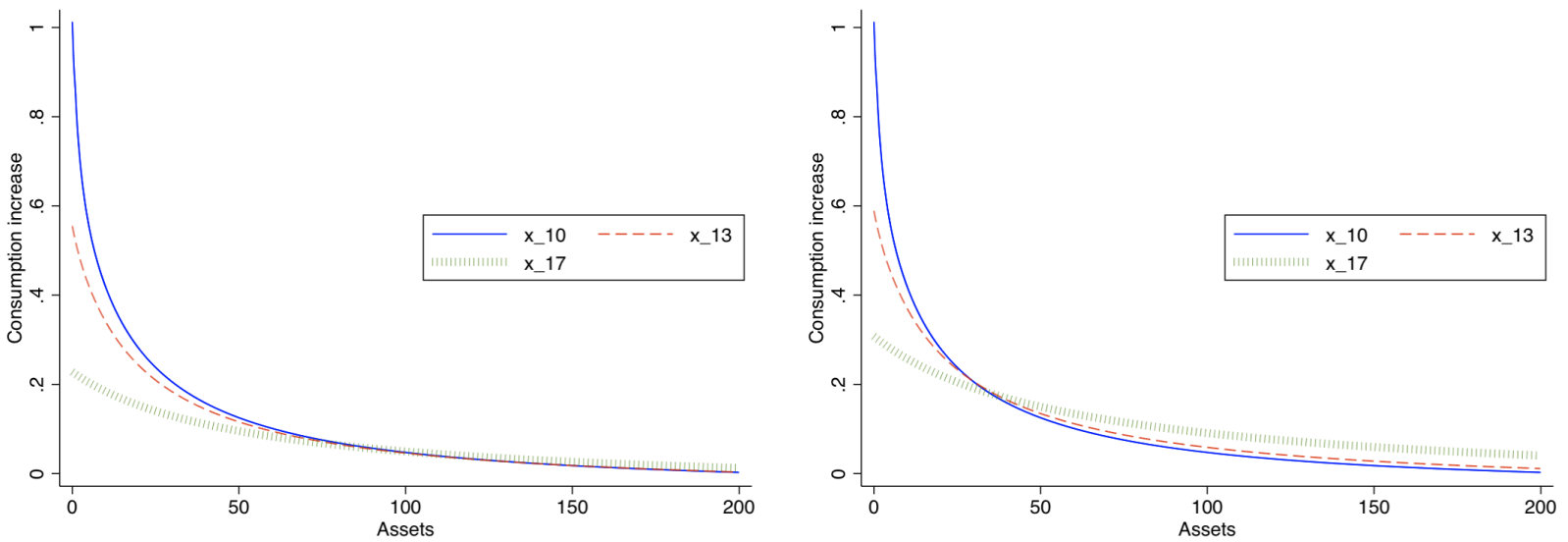

Figure 6. Price constant welfare gains for inexperienced (left) and experienced (right) individuals.
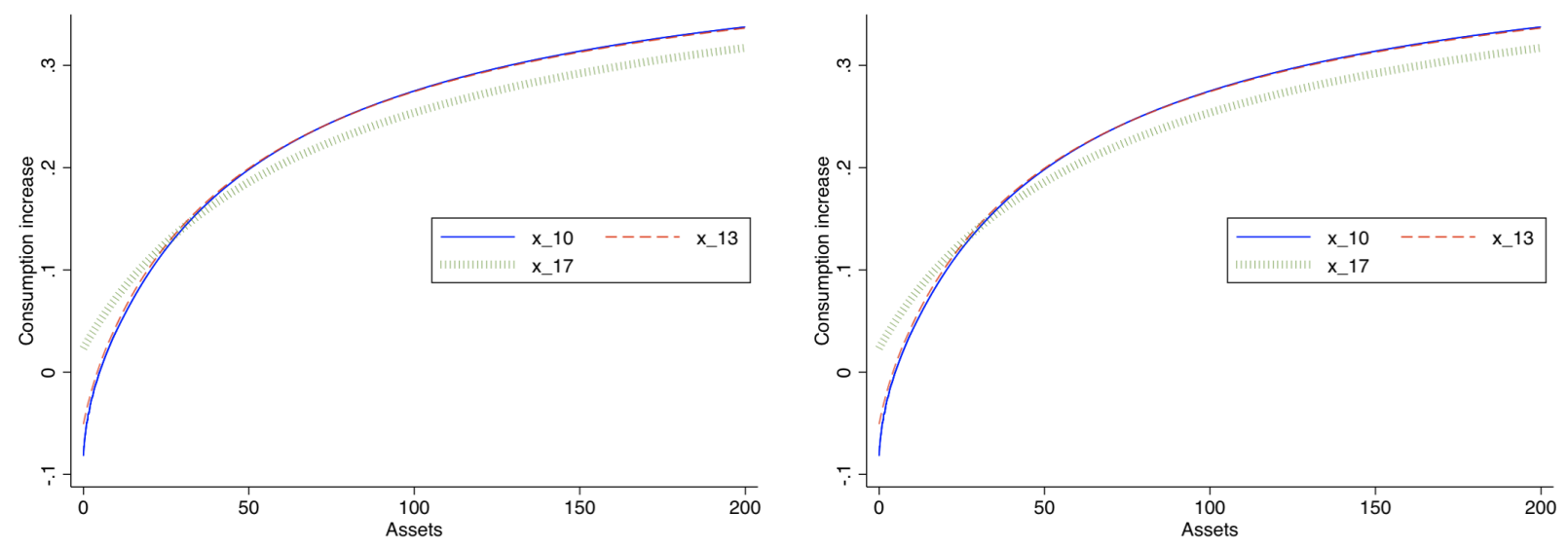

Figure 7. GE welfare gains for inexperienced (left) and experienced (right) individuals. 


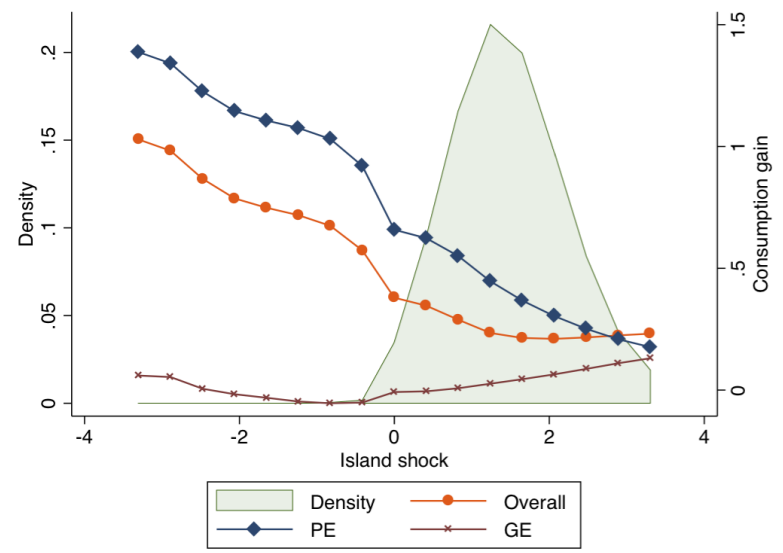

Figure 8. Distribution of welfare gains by island and experience level: overall, price-constant, and general equilibrium effects.

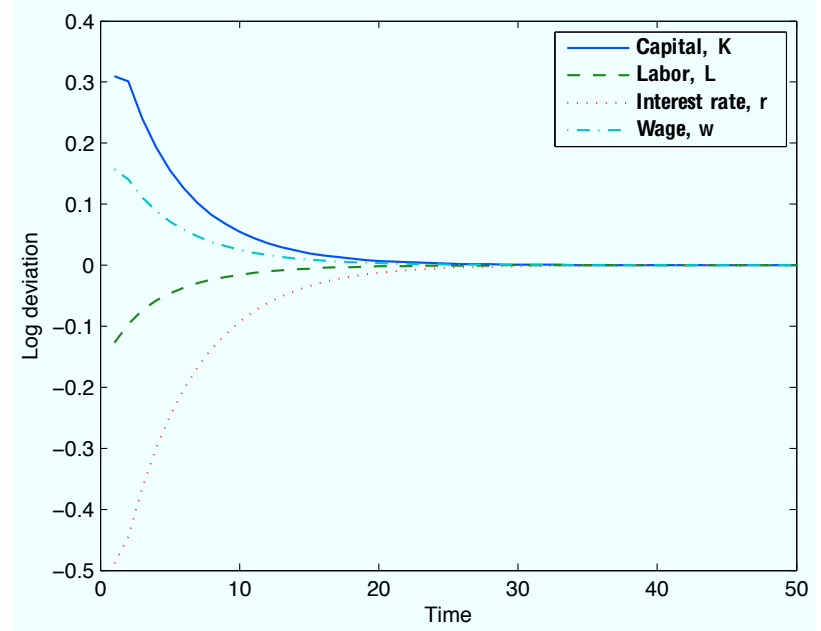

Figure 9. Transition to the complete markets steady state. 


\subsection{Robustness}

To be added.

\section{Policy experiment: the Effects of a Training Subsidy}

To be added.

\section{Occupational Mobility among the Young}

We assume in our benchmark model that agents are infinitely-lived. This is convenient for expositional purposes; however, an important limitation is that in such a model, we abstract from life-cycle variation in occupational mobility. In fact, because borrowing constraints are more likely to be binding for young agents, the effect of market incompleteness can be more significant for these agents. In this section we argue that this is quantitatively significant.

To model young agents, we consider the thought experiment of introducing a cohort of small measure of agents into the steady state of our benchmark model. We imagine that the initial occupation of each worker in this cohort is randomly drawn according to the ergodic distribution of island productivities, $\Psi(\cdot)$. Each agent in the cohort starts off with no assets. Because this cohort is small, it does not affect the equilibrium, and in particular, equilibrium prices $w$ and $r$ are unchanged. It follows that the optimal policy for agents in the new cohort are the same as those in the benchmark model. The only difference between the new cohort and other agents is that the cross-sectional distribution of the new agents by island productivities, experience, and assets are not the same as the ergodic distribution $\mu$ (the newborns are all inexperienced and have zero assets, and their productivity distribution is dominated, in the sense of first-order stochastic dominance, by the distribution for existing agents). Finally, to understand the effects of incomplete markets on occupational mobility and on welfare, we also conduct the same experiment in a complete markets environment. We do this in the complete markets steady-state, although the results would be essentially unchanged if we conducted a partial equilibrium analysis in the sense of the previous section by keeping $w$ and $r$ at the values from the incomplete markets steady state.

The results of this experiment are shown in Figures 10, 11, and 12. Each graph presents a simulated time series of a particular variable for the cohort of newborn agents, the solid blue line showing the benchmark (incomplete markets) model and the red dashed line the complete markets model. The age of the agents in the cohort under study (that is, the number of periods since their introduction into the model) is measured on the horizontal axis in each plot. Figure 10 shows mobility. While even in steady state occupational mobility is higher under complete markets, the difference is much starker for the new cohort of financially-constrained agents. Initial mobility exceeds 50 percent annually for several years under complete markets, as initially-unlucky agents seek more productive occupations; in the incomplete markets environment, on the other hand, young agents cannot pay the mobility cost and so do not move. The right panel of Figure 10 shows 

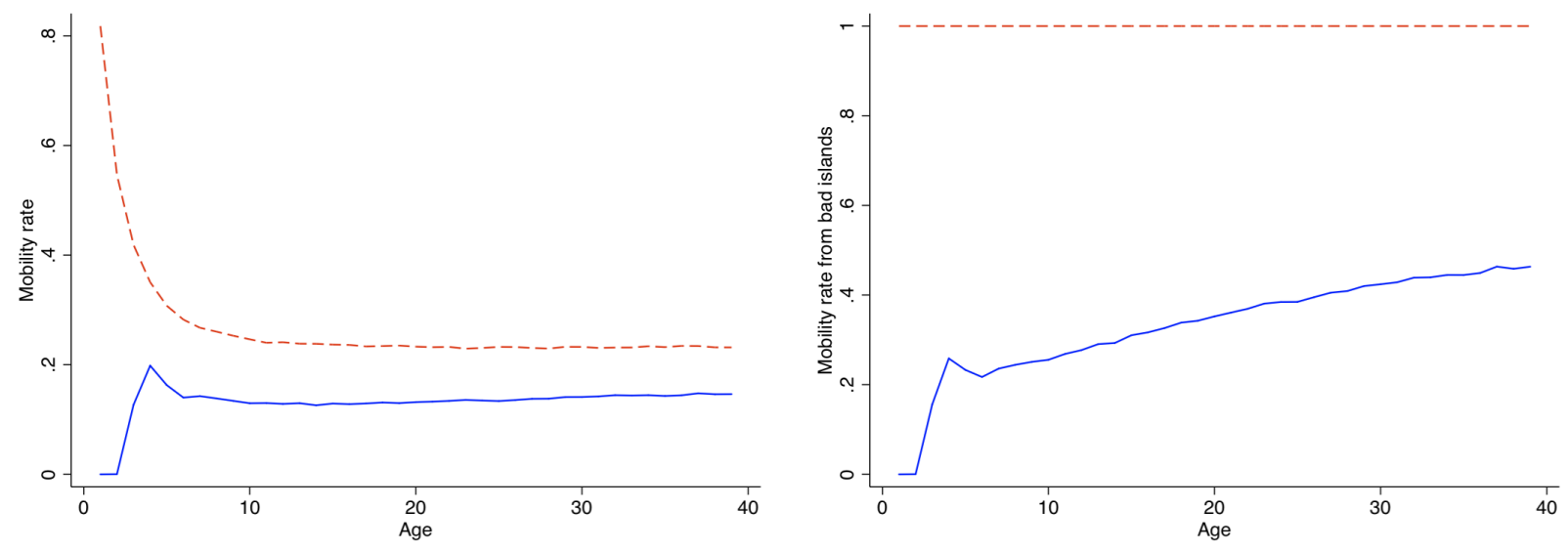

Figure 10. Young worker experiment. Blue solid line: benchmark; red dashed line: complete markets. Left panel: Average mobility, by cohort age.

Right panel: Mobility rate conditional on positive expected present discounted value of moving, by cohort age.

this difference in mobility even more starkly, by showing mobility rates conditional on a worker being located on an island with productivity low enough that the expected present discounted value of wages of the worker is increased by leaving the island. Under complete markets, any worker on such an island leaves immediately, while in the incomplete-markets benchmark, most workers on such islands choose not to pay the cost of moving.
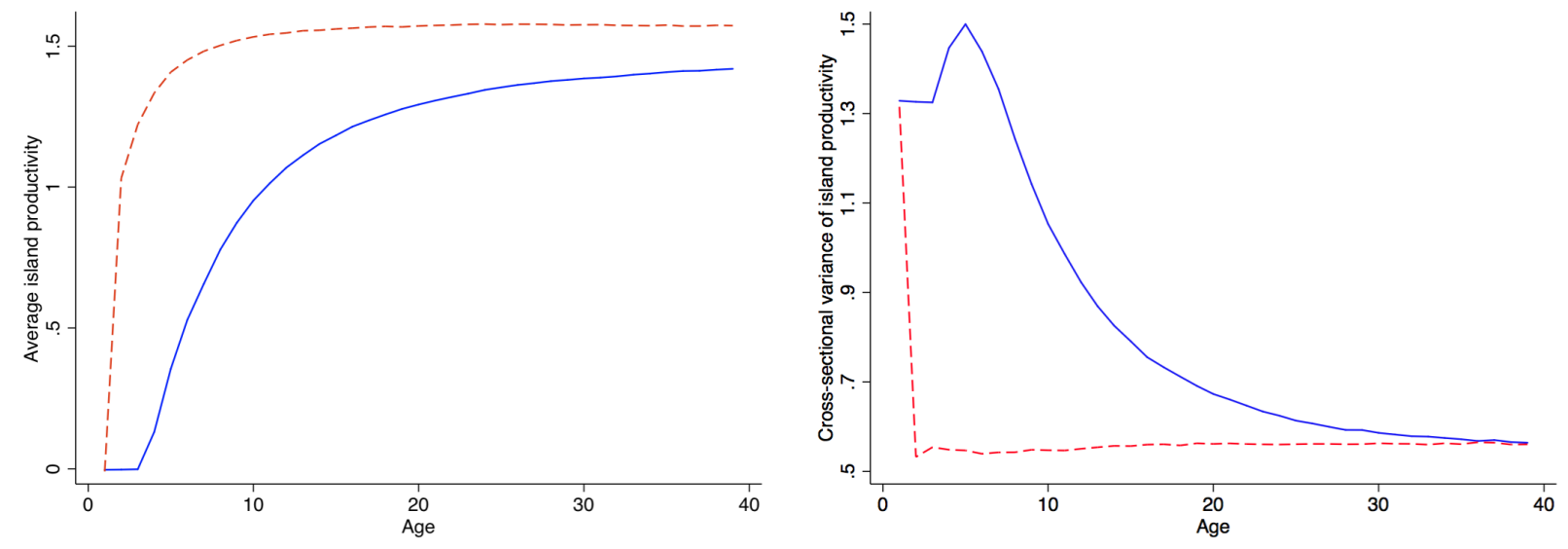

Figure 11. Young worker experiment. Blue solid line: benchmark; red dashed line: complete markets. Left panel: Average island log productivity, by cohort age.

Right panel: Cross-sectional variance of island log productivity, by cohort age.

Figure 11 shows the effect of reduced mobility under incomplete markets for productivity. The left panel shows average log island productivity. In both market environments, average productivity improves with cohort age as workers relocate out of unproductive occupations, but the transition is much more protracted under incomplete markets. The differences in expected log occupation productivity for young workers substantially exceed the long-run differences. The right panel of 
Figure 11 shows the cross-sectional variance of productivity, which also falls much more slowly under incomplete markets.
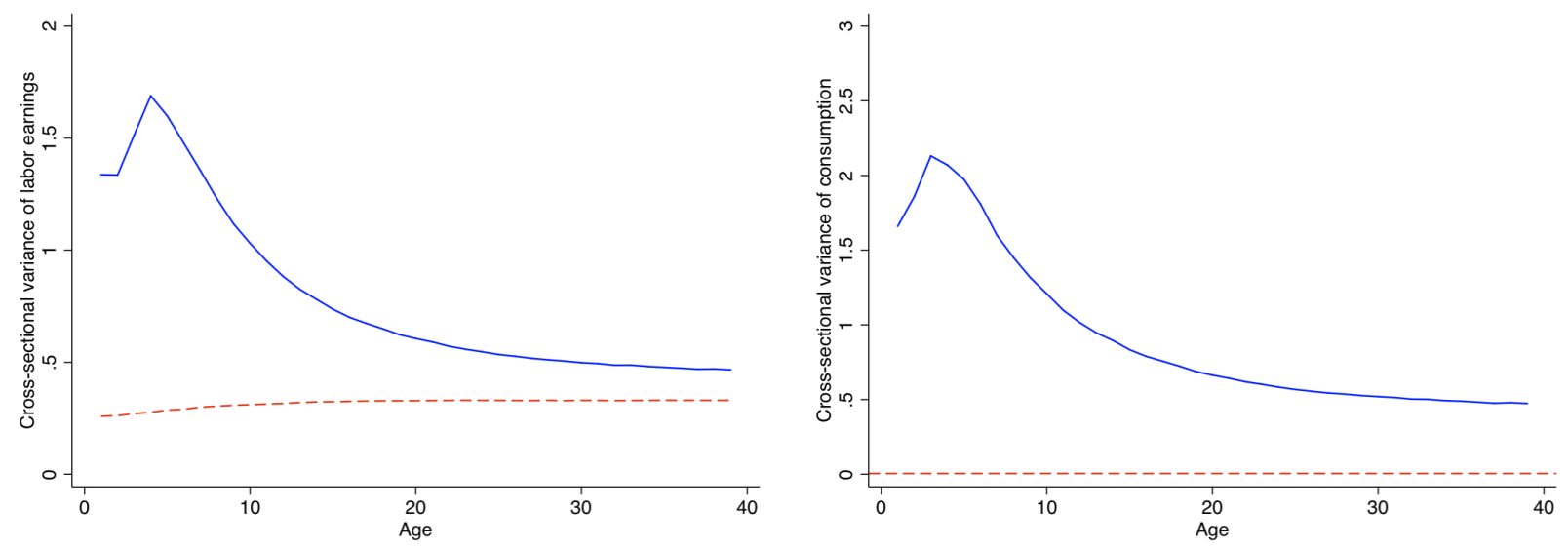

Figure 12. Young worker experiment. Blue solid line: benchmark; red dashed line: complete markets. Left panel: Variance of log labor income conditional on working, by cohort age. Right panel: Variance of log consumption, by cohort age.

Finally, Figure 12 shows the cross-sectional variance of labor earnings (conditional on employment) and of consumption. It is striking that the variance of log labor income is hump-shaped in the benchmark: initially-lucky agents increase their assets, become better-insured, and move away from their occupation if it receives a negative productivity shock, while initially-unlucky agents cannot use this insurance mechanism. Under complete markets the cross-sectional variance of log labor income is essentially constant. As always, consumption shows the importance of complete markets most strikingly: in the incomplete market environment, the variance of log consumption tracks that of labor income ${ }^{10}$ while under complete markets, consumption is essentially constant across agents. ${ }^{11}$.

In summary, the effects of market incompleteness are substantially exacerbated for young, poorly-insured agents in our model. This suggests that average welfare effects could be even larger in a life-cycle version of our model. Constructing such a model would allow us to incorporate two important life-cycle effects that are missing in the infinite-horizon model in the current paper. First, finite horizon effects are quantitatively relevant near the end of the life-cycle, since the future income gain from occupational mobility decreases as the remaining working lifetime falls. Second, for the model to be consistent with the observed decline in occupational mobility by age (Kambourov and Manovskii, 2008), it is probably important to allow for agents to learn about their own occupational match quality, as in Neal (1999). We leave constructing a model with these features for future research.

\footnotetext{
${ }^{10}$ Note that the distribution of labor earnings reported in the left panel of Figure 12 omits agents who switch occupations and have zero labor income; it is therefore not surprising that consumption variance (for all agents) can exceed income variance for the employed. This is reinforced by the highly persistent nature of occupation productivity shocks.

${ }^{11}$ Consumption is precisely equated across agents under complete markets if agents can insure themselves, behind the veil of ignorance, against their initial island productivity. It is very small (0.0052) if this market is missing.
} 


\section{Conclusion}

In this paper we study the effects of financial market incompleteness on occupational mobility, motivated by the fact that occupation-level earnings shocks are large and highly persistent, and therefore difficult for workers to insure against. Occupational choice is modeled using an equilibrium search model where the returns to working in an occupation are stochastic, and occupational mobility is costly. Unlike the existing literature on occupational mobility, we relax the assumption of complete markets and allow agents to self-insure by saving using a risk-free bond. Relative to the existing literature on incomplete markets, our paper adds a novel feedback mechanism from incomplete markets to the process for future labor income.

Our calibrated model suggests that the effects of market incompleteness on occupational mobility are quantitatively large. Relative to a comparable complete markets framework, mobility in our preferred calibration is 7.3 percent lower. Importantly, this leads to a reduction in labor productivity as more agents work in less productive occupations. We find that the welfare costs of market incompleteness can be as large as 25 percent of lifetime consumption.

We see two important and complementary directions of future research. First, our model has the prediction that agents with low assets find mobility too costly and therefore end up with lower future labor income. Given that this is the key mechanism in our model, verifying this prediction empirically with panel data on wealth, employment, and wages is crucial. Second, our welfare analysis suggests that the effects of market incompleteness can be larger when taking into account life-cycle differences across agents. Extending our model along this dimension is another potentially fruitful avenue to investigate.

\section{References}

Aiyagari, S. Rao. 1993. "Uninsured Idiosyncratic Risk and Aggregate Saving." Working Paper 502, Federal Reserve Bank of Minneapolis, Minneapolis, MN.

- 1994. "Uninsured Idiosyncratic Risk and Aggregate Saving." Quarterly Journal of Economics 109 (3):659-84.

Alvarez, Fernando and Marcelo Veracierto. 1999. "Labor-Market Policies in an Equilibrium Search Model." In NBER Macroeconomics Annual, vol. 14, edited by Ben S. Bernanke and Julio J. Rotemberg. Cambridge, MA: MIT Press, 265-304.

Banerjee, Abhijit V. and Andrew F. Newman. 1993. "Occupational Choice and the Process of Development." Journal of Political Economy 101 (2):274-298.

Bewley, Truman F. 1986. "Stationary Monetary Equilibrium with a Continuum of Independently Fluctuating Consumers." In Contributions to Mathematical Economics in Honor of Gerard Debreu, edited by Werner Hildenbrand and Andreu Mas-Colell. Amsterdam: North-Holland, 79-102. 
Buera, Francisco J. 2007. "Persistence of Poverty, Financial Frictions, and Entrepreneurship." Unpublished.

. 2009. "A dynamic model of entrepreneurship with borrowing constraints: theory and evidence." Annals of Finance 5 (3-4):443-464.

Buera, Francisco J. and Yongseok Shin. 2011. "Self-insurance vs. self-financing: A welfare analysis of the persistence of shocks." Journal of Economic Theory 146 (3):845-862.

Cagetti, Marco and Mariacristina De Nardi. 2006. "Entrepreneurship, Frictions, and Wealth." Journal of Political Economy 114 (5):835-870.

Chang, Yongsung and Sun-Bin Kim. 2006. "From Individual to Aggregate Labor Supply: A Quantitative Analysis Based on a Heterogeneous Agent Macroeconomy." International Economic Review 47 (1):1-27.

Evans, David S. and Boyan Jovanovic. 1989. "An Estimated Model of Entrepreneurial Choice under Liquidity Constraints." Journal of Political Economy 97 (4):808-827.

Filmer, Deon and Lant Pritchett. 1999. "The Effect of Household Wealth on Educational Attainment: Evidence from 35 Countries." Population and Development Review 25 (1):85-120.

Goldin, Claudia. 2006. "The Quiet Revolution That Transformed Women's Employment, Education, and Family." American Economic Review 96 (2):1-21.

Heathcote, Jonathan, Kjetil Storesletten, and Giovanni L. Violante. 2008. "Insurance and opportunities: A welfare analysis of labor market risk." Journal of Monetary Economics 55 (3):501-525.

Heckman, James J., Robert J. Lalonde, and Jeffrey A. Smith. 1999. "The economics and econometrics of active labor market programs." In Handbook of Labor Economics, vol. 3A, edited by Orley C. Ashenfelter and David Card, chap. 31. Amsterdam: Elsevier, 1865-2097.

Huggett, Mark. 1993. "The risk-free rate in heterogeneous-agent incomplete-insurance economies." Journal of Economic Dynamics and Control 17 (5-6):953-969.

Kambourov, Gueorgui and Iourii Manovskii. 2008. "Rising Occupational and Industry Mobility in the United States: 1968-97." International Economic Review 49 (1):41-79.

- 2009a. "Occupational Mobility and Wage Inequality." Review of Economic Studies $76(2): 731-759$.

- 2009b. "Occupational Specificity of Human Capital." International Economic Review $50(1): 63-115$.

Katz, Lawrence F. and David H. Autor. 1999. "Changes in the Wage Structure and Earnings Inequality." In Handbook of Labor Economics, edited by Orley C. Ashenfelter and David Card, chap. 26. Amsterdam: Elsevier, 1463-1555. 
Krusell, Per, Toshihiko Mukoyama, Richard Rogerson, and Ayşegül Şahin. 2008. "Aggregate implications of indivisible labor, incomplete markets, and labor market frictions." Journal of Monetary Economics 55 (5):961-979.

Lucas, Robert E., Jr. and Edward C. Prescott. 1974. "Equilibrium Search and Unemployment." Journal of Economic Theory 7 (2):188-209.

Marcet, Albert, Francesc Obiols-Homs, and Philippe Weil. 2007. "Incomplete markets, labor supply, and capital accumulation." Journal of Monetary Economics 54 (8):2621-2635.

McCall, Brian P. 1990. “Job Matching: A Test of Sorts.” Journal of Political Economy 98 (1):45-69.

Miller, Robert A. 1984. "Job Matching and Occupational Choice." Journal of Political Economy $92(6): 1086-1120$.

Neal, Derek. 1995. "Industry-Specific Human Capital: Evidence from Displaced Workers." Journal of Labor Economics 13 (4):653-677.

- 1999. "The Complexity of Job Mobility among Young Men." Journal of Labor Economics $17(2): 237-261$.

Parent, Daniel. 2000. "Industry-Specific Capital and the Wage Profile: Evidence from the National Longitudinal Survey of Youth and the Panel Study of Income Dynamics." Journal of Labor Economics 18 (2):306-323.

Pavan, Ronni. 2011. "Career Choice and Wage Growth." Journal of Labor Economics 29 (3):549587.

Pijoan-Mas, Josep. 2006. "Precautionary savings or working longer hours?" Review of Economic Dynamics 9 (2):326-356.

Quadrini, Vincenzo. 2000. "Entrepreneurship, Saving and Social Mobility." Review of Economic Dynamics 3 (1):1-40.

Şahin, Ayşegül, Joseph Song, Giorgio Topa, and Giovanni L. Violante. 2011. "Measuring Mismatch in the U.S. Labor Market." Federal Reserve Bank of New York mimeo.

Vereshchagina, Galina and Hugo A. Hopenhayn. 2009. "Risk Taking by Entrepreneurs." American Economic Review 99 (1):1808-1830. 